\title{
REFORMA DA EDUCAÇÃO PROFISSIONAL NOS ANOS 1990: o Brasil segue o guia neoliberal
}

\author{
Francisco das Chagas Silva Souza ${ }^{1}$ \\ Ana Paula Marinho de Lima²
}

\begin{abstract}
RESUMO
Na década de 1990, o governo brasileiro realizou uma série de reformas embasadas nos princípios neoliberais de competitividade, individualidade e liberdade do mercado. O objetivo deste artigo é compreender o processo como ocorreram essas reformas e analisar os seus efeitos na Educação Profissional. Para tanto, desenvolveu-se uma pesquisa bibliográfica tendo por base pesquisadores como: Bresser-Pereira (1997, 1996), Shiroma, Moraes e Evangelista (2011), Frigotto (2006), Frigotto e Ciavatta (2003, 2012), Martins (2000), Cunha (2005), dentre outros. Também foi realizada uma pesquisa documental a partir da leitura e da análise dos documentos que implantaram a Reforma da Educação Profissional. A pesquisa evidenciou que essa Reforma, seguindo os princípios neoliberais de competitividade e meritocracia, teve como foco a formação de mão de obra para suprir as necessidades do mercado. Também foi oficializada a histórica dualidade nas políticas educacionais brasileiras ao se separar o Ensino Médio do Técnico.
\end{abstract}

Palavras-chave: Neoliberalismo. Reforma da Educação Profissional. Decreto $N^{\circ}$ 2.208/1997.

\section{PROFESSIONAL EDUCATION REFORM IN THE 1990S: Brazil follows the neoliberal guide}

\begin{abstract}
In the 1990s, the Brazilian government carried out a series of reforms based on the neoliberal principles of competitiveness, individuality, and market freedom. The goal of this article is to understand how these reforms occurred and to analyze their effects on Professional Education. Therefore, bibliographic research was developed based on researchers such as Bresser-Pereira (1997, 1996), Shiroma, Moraes and Evangelista (2011), Frigotto (2006), Frigotto and Ciavatta (2003, 2012), Martins (2000), Cunha (2005), among others. Documentary research was also carried out from the reading and analysis of the documents that implemented the Professional Education Reform. The research showed that this Reform, following the neoliberal principles of competitiveness and meritocracy, focused on the training of the labor force to

\footnotetext{
${ }^{1}$ Doutor em Educação (UFRN). Professor dos Programas de Pós-Graduação em Educação Profissional (PPGEP/IFRN), em Ensino (UERN/IFRN/Ufersa) e em Educação Profissional e Tecnológica (ProfEPT/IFRN). Orcid iD: https://orcid.org/0000-0003-4783-3731. E-mail: chagas.souza@ifrn.edu.br

2 Doutoranda em Educação Profissional (PPGEP/IFRN). Licenciatura em Pedagogia (UERN). Mestrado em Ensino (POSENSINO), Associação ampla UERN/IFRN/Ufersa, com bolsa da Coordenação de Aperfeiçoamento de Pessoal de Nível Superior (CAPES), em 2019-2020. Orcid iD: https://orcid.org/0000-0002-9721-9812. E-mail: ninapaula01@hotmail.com
} 
supply the needs of the market. The historic duality in Brazilian educational policies was also made official by separating High School from Technical School.

Palavras-chave: Neoliberalism. Professional Education Reform. Decree № 2.208/1997.

\section{LA REFORMA DE LA EDUCACIÓN PROFESIONAL EN LOS AÑOS 1990: el Brasil sigue el guía neoliberal}

\section{RESUMEN}

En la década de 1990, el gobierno brasileño realizó una serie de reformas respaldadas en los principios neoliberales de competitividad, individualidad y libertad del mercado. El objetivo de este artículo es comprender el proceso como ocurrieron esas reformas y analizar los efectos de esta Educación Profesional. Para tanto, se desarrolló una pesquisa bibliográfica teniendo por base investigadores como: Bresser-Pereira (1997, 1996), Shiroma, Moraes e Evangelista (2011), Frigotto e Ciavatta (2003, 2012), Martins (2000), Cunha (2005), entre otros. También fue realizada una pesquisa documental a partir de la lectura y análisis de los documentos que implantaron la Reforma de la Educación Profesional. La pesquisa evidenció que esa Reforma, siguiendo los principios neoliberales de competitividad y meritocracia, tuvo como enfoque la formación de mano de obra para satisfacer las necesidades del mercado. También fue oficializada la histórica dualidad en las políticas educacionales brasileñas al separarse la enseñanza secundaria de la enseñanza técnica.

Palabras clave: Neoliberalismo. Reforma de la educación profesional. Decreto $n^{\circ}$ $2.208 / 1997$.

\section{INTRODUÇÃO}

Na década de 1990, o governo brasileiro implementou uma série de reformas no âmbito da educação, em especial, da Educação Profissional (EP). Essas reformas eram alicerçadas nos princípios neoliberais e exigiam da EP uma revisão no seu currículo e nas ofertas, de modo a formar um trabalhador capaz de exercer múltiplas tarefas e de facilmente se adaptar às mudanças e incertezas do mercado.

Para assegurar ao mercado mão de obra qualificada e rápida, o Governo Federal criou, em fins da década de 1990, o Decreto n².208/1997 e outras medidas legais que permitiram um currículo com cursos rápidos, modulares, e que divorciava a formação geral da profissional.

Nosso objetivo, neste artigo, é compreender o processo que desencadeou essas reformas e os impactos destas na EP. Para tanto, realizamos, inicialmente, uma pesquisa bibliográfica tendo por base 
pesquisadores como: Bresser-Pereira (1997, 1996); Shiroma, Moraes e Evangelista (2011), Frigotto (2006), Frigotto e Ciavatta (2003, 2012) dentre outros que nos auxiliaram na compreensão das reformas.

Em seguida, procedemos uma análise na legislação que implantou a Reforma da EP: O Decreto $n^{\circ} 2.208 / 1997$ e as Portarias $n^{\circ} 646 / 1997$ e $n^{\circ}$ 1005/1997. Essas fontes, como as demais, são marcadas pelo seu "lugar de produção", e falam, clara ou veladamente, da sociedade que a produziu (BARROS, 2020). Conforme Stamatto (2012, p. 277), "a lei educacional é um indício, uma pista do passado". Mas, salienta a autora, a lei "não é um vestígio qualquer do passado, pois contempla a intencionalidade de seu registro por poderes instituídos em uma determinada época".

Este artigo está dividido em duas seções. Na primeira, mediante uma pesquisa bibliográfica, comentamos a respeito das ideias neoliberais, suas origens, sua "popularidade" na década de 1970 e sua implantação, no Brasil, nos anos 1990. Na seção seguinte, discutimos a Reforma da EP, enfocando a legislação que the deu suporte e, pari passu, apresentando nossas ponderações e as de outros pesquisadores no tocante ao tema.

\section{O RECEITUÁRIO NEOLIBERAL: A REFORMA DO ESTADO E DA EDUCAÇÃO PROFISSIONAL}

O neoliberalismo tem seu marco na obra "O Caminho da Servidão", de Friedrich Hayek, publicada em 1944. Nela, Hayek (2010) afirmava que princípios como individualismo e liberdade deveriam ser os condutores do processo produtivo humano. Esse economista, ao realizar uma análise do caminho percorrido pela humanidade, delineava outros novos camios que precisariam ser seguidos para que a sociedade alcançasse 0 desenvolvimento e a liberdade em sua plenitude. Defendia que, ao ser dotado de inteira autonomia, o homem, soberanamente, escolhe e age conseguindo o que deseja, tendo, assim, poder sobre o próprio destino. Desse modo, Hayek apresenta os atributos do individualismo.

Para Hayek (2010), a liberdade está ligada à independência do setor econômico das limitações impostas pelo Estado. Qualquer determinação nesse sentido limitaria não só a liberdade do comércio, mas também a 
política de um país, negando ao indivíduo o poder de conduzir a sua própria vida.

Consoante Martins (2000), tais ideias ficaram como que "incubadas", mas mantiveram-se fortes o suficiente entre os seus simpatizantes, para continuarem vivas até que, em momento propício, elas fossem propagadas, o que ocorreu na década de 1970, com a crise do petróleo, a qual, dentre outros efeitos, trouxe o declínio do Estado do bem-estar social (Welfore State).

Essa crise significou a exaustão do modelo de acumulação fordista/taylorista de produção, apontando para um novo regime marcado pela flexibilização dos processos de trabalho. Princípios como competitividade, individualismo, desregulamentação e Estado-Mínimo ganharam notoriedade como alternativa de superar o endividamento causado pela crise, iniciando sua implementação pela Inglaterra, seguida de outros países como Estados Unidos, Alemanha e Dinamarca, chegando à América Latina, no Chile.

Martins (2000, p. 61) cita as seguintes assertivas como centrais do pensamento dos novos liberais que se apoiavam nas ideias de Hayek:

a) A crença de que a desigualdade é o motor do desenvolvimento individual, que acarretaria como consequência necessária uma elevação do nível de bem-estar social para muitos outros indivíduos, mas não para todos, já que se assim ocorresse se quebraria o próprio motor de seu desenvolvimento;

b) O combate às políticas de bem-estar social, como ação urgente a ser efetivada, uma vez que a Europa, adotando esse modelo de proteção coletiva para seus indivíduos, poderia estar comprometendo o propalado motor de desenvolvimento social - a desigualdade;

c) O combate ao movimento sindical, organizado e com forte poder de pressão, que exige a diminuição das desigualdades econômicas, bem como a manutenção e a expansão das políticas de bem-estar social, e,

d) O combate à presença forte do Estado em todas as instâncias sociais, sobretudo na econômica, já que a iniciativa privada, afirmavam, é mais propensa à defesa das individualidades e da liberdade para a economia.

Emerge uma nova forma de organização do trabalho, a reestruturação produtiva, estimulada pela globalização que expandia o processo de internacionalização produtiva e financeira, e estava associada à revolução tecnológica. Essas mudanças foram fundamentais para 
profundas transformações no mundo do trabalho, marcadas por uma nova organização e por formas de processos de produção disseminadas pelo mundo nas décadas de 1980 e 1990.

Nesse cenário, direitos sociais como saúde, educação, pleno emprego, previdência, dentre outros, são desarticulados, transitando da condição de direito à de propriedade. Para Gentili (1996, p.20), "O modelo do homem neoliberal é o cidadão privatizado, o consumidor", ou seja, há uma reconceituação da percepção de cidadania, por intermédio de uma revalorização da ação do indivíduo como sujeito que luta para conquistar mercadorias e propriedades de várias naturezas.

No Brasil, o fortalecimento do discurso neoliberal iniciou-se no governo do presidente Fernando Collor de Mello (1990-1992) que extinguiu instituições públicas e privatizou várias estatais. Em 1992, com o seu impeachment, assumiu a presidência o vice-presidente, Itamar Franco, o qual nomeou, para o Ministério da Fazenda, o sociólogo Fernando Henrique Cardoso, que implementou o Plano Real, pretendendo controlar a inflação e estabilizar a economia do país. O Plano Real não só conseguiu equilibrar a crise econômica, mas também foi primordial para a ascensão do então ministro à presidência da República.

Ao assumir a presidência, em 1995, Fernando Henrique Cardoso já havia se articulado com os organismos internacionais e elaborado projetos que previam a privatização de estatais brasileiras e a descentralização do Estado. Para Silveira (2010, p. 52), as condições políticas criadas com a eleição de Fernando Henrique Cardoso permitiram "[...] a implementação de um conjunto de reformas voltadas para uma nova ordem sociometabólica centrada no mercado. Além da ênfase nas reformas econômicas [...] desencadeia-se o processo das reformas constitucionais".

Assim, é sob as premissas neoliberais que ocorre a Reforma do Estado na década de 1990. A retórica neoliberal alcança seu êxito, que se resume, segundo Martins (2000), em controlar o processo inflacionário, a derrota do movimento sindical (ainda que não permanentemente), o reestabelecimento dos lucros da iniciativa privada e o que, para o autor, 
pode ser o maior deles, o de estabelecer como senso comum a visão de que a única forma de conduzir a economia, o país e o mundo é admitindose e efetivando-se as suas próprias premissas.

As reformas vinham em sentido oposto às políticas do Estado de BemEstar Social e às experiências do socialismo real. Eram reestabelecidos os mecanismos de mercado, abraçando a ideia de que a liberdade do mercado conduz à prosperidade, enquanto as políticas sociais, à escravidão. Para Frigotto e Ciavatta (2003, p. 95), o documento conhecido como "Consenso de Washington" "[...] balizou a doutrina do neoliberalismo ou neoconservadorismo que viria a orientar as reformas sociais nos anos de 1990. É neste cenário que emerge a noção de globalização carregada, ideologicamente, por um sentido positivo".

Como um complexo processo de construção hegemônico, o neoliberalismo não apenas conquista espaço, mas também se apresenta como a única alternativa a ser seguida pelos países em crise, configurandose como uma doutrina, pregando a ideologia do "Estado Mínimo".

Para dar início à Reforma do Estado, o presidente Fernando Henrique Cardoso criou o Ministério da Administração e Reforma do Estado (MARE). Redefine-se a agenda pública com base no mercado e com ênfase nas reformas econômicas, como a privatização, a liberação comercial e a abertura externa. Além de desencadear reformas constitucionais, "Tem início uma fase de desconstrução legal e institucional, que abriria o caminho para a refundação do Estado e da sociedade, de acordo com o paradigma consagrado internacionalmente" (SILVEIRA, 2010, p. 52).

A condução do MARE coube ao economista Luiz Carlos Bresser Pereira, que, após realizar um diagnóstico referente à administração pública no país, publicou o documento "Plano Diretor da Reforma do Aparelho do Estado" (PDRAE), no qual, a crise do Estado definia-se:

(1) como uma crise fiscal, caracterizada pela crescente perda do crédito por parte do Estado e pela poupança pública que se torna negativa; (2) o esgotamento da estratégia estatizante de intervenção do Estado, a qual se reveste de várias formas: o Estado do bem-estar social nos países desenvolvidos, a estratégia de substituição de importações no terceiro mundo, e o estatismo nos 
países comunistas; e (3) a superação da forma de administrar o Estado, isto é, a superação da administração pública burocrática (BRASIL, 1995, p. 10-11).

O PDRAE apresentou propostas para a reforma por considerá-la "[...] indispensável para consolidar a estabilização e assegurar o crescimento sustentado da economia. Somente assim será possível promover a correção das desigualdades sociais e regionais" (BRASIL, 1995, p. 6). Tais justificativas motivaram uma série de transformações, dentre as quais, a Reforma do Aparelho do Estado, com o intuito de aumentar a sua governança, ou seja, a capacidade de implementar, de forma eficiente, as políticas públicas; um exemplo seriam as voltadas à educação.

O documento partia da constatação de que a crise econômica latino-americana era de fato uma crise do Estado. Afirmava que este havia se distanciado de suas funções precípuas para atuar com ênfase na esfera produtiva. Isso se devia ao modelo de desenvolvimento de substituição das importações, adotado desde os anos de 1930 (BRASIL, 1995). Assim, o PDRAE indicou como elementos do projeto de Reforma do Estado:

(1) o ajustamento fiscal duradouro; (2) reformas econômicas orientadas para o mercado, que, acompanhadas de uma política industrial e tecnológica, garantam a concorrência interna e criem as condições para o enfrentamento da competição internacional; (3) a reforma da previdência social; (4) a inovação dos instrumentos de política social, proporcionando maior abrangência e promovendo melhor qualidade para os serviços sociais; e (5) a reforma do aparelho do Estado, com vistas a aumentar sua "governança", ou seja, sua capacidade de implementar de forma eficiente políticas públicas (BRASIL, 1995. p. 11).

A Reforma do Estado deve ser compreendida no contexto da redefinição do seu papel, ao deixar de ser o responsável direto pelo desenvolvimento econômico e social, pela via da produção de bens e de serviços, para fortalecer-se na função de promotor e regulador desse desenvolvimento (BRESSER-PEREIRA, 1997). Logo, ao Estado caberia apenas a função de equilibrar as relações entre mercado e a sociedade, fiscalizando e certificando as demandas advindas do novo modelo econômico.

Para os dirigentes da Reforma, tais mudanças tirariam o Brasil da crise e levaria o país ao progresso econômico, alimentado pela globalização. A 
ideia de desenvolvimento humano, como processo histórico e de realização dos direitos humanos, é redirecionada, adotando-se a ideia iluminista de progresso (CUNHA, 2005).

Os direitos dos indivíduos deixam de se fixar nas suas necessidades básicas para depender, unicamente, do desempenho do seu trabalho frente ao mercado capitalista. Apesar disso, a Reforma sustentou-se no discurso de diminuição da desigualdade, como consta no PDRAE (BRASIL, 1995, p. 44). Com o objetivo de melhorar a economia e, consequentemente, contribuir com a redução da desigualdade, Bresser-Pereira (1996, p.16-17) aponta, como solução, a privatização ou a publicização dos serviços sociais.

Para isso, foi preciso uma transformação em três dimensões: a institucional legal, por meio da reforma da Constituição e das leis do país; a cultural, com a internalização de uma nova visão do que seja a administração pública; e a da gestão, no lugar em que se concretiza a reforma (BRESSER-PEREIRA, 1997).

Em síntese, a Reforma do Estado é pensada a partir de quatro elementos principais, a saber: a delimitação do tamanho do Estado, a redefinição do papel regulador do Estado, a recuperação da governança e o aumento da governabilidade. Dessa forma, os dispositivos de privatização, publicização e terceirização correspondiam à delimitação do tamanho do Estado; o papel de regulação diz respeito ao nível de intervenção do governo no mercado; a recuperação da governança consistiu nas questões financeira, estratégica e administrativa; e o aumento da governabilidade relaciona-se às maneiras de legitimar o governo e de adaptar as instituições para que o interesse público fosse executado (BRESSER-PEREIRA, 1997).

Segundo Shiroma, Moraes e Evangelista (2011), a educação ganha notoriedade nesse cenário, apoiada pela literatura internacional, retomando ideias da Teoria do Capital Humano, desenvolvida por Theodore Schultz, nos anos 1960, que, conforme as autoras, via a educação como um dos determinantes da competitividade entre os países. "Alegava-se que o novo paradigma produtivo demandava requisitos diferenciados de educação geral e qualificação profissional dos trabalhadores" (SHIROMA; MORAES; 
EVANGELISTA, 2011, p. 47). Portanto, de forma mecânica e repentina, é atribuído à educação "o condão" que sustentaria a competitividade nos anos de 1990.

Oliveira (2003, p. 7) destaca que "A educação serve como 'válvula de escape' para a afirmação do modelo implementado [...]". Novos conceitos, como competência e empregabilidade, aliados a um referencial pedagógico que define um critério particular de qualidade na educação, conduzem-na aos interesses diretos das elites empresariais, e estas, com a justificativa da produção flexível, consideram-na fundamental para uma economia mais produtiva e competitiva.

Para Shiroma, Moraes e Evangelista (2011) e Oliveira (2003), essa função destinada à educação alimentava uma antiga máxima salvacionista, a qual se materializou com a intervenção dos organismos multilaterais. Essa situação pode ser entendida por meio da análise realizada por Oliveira (2003), ao concluir que o governo brasileiro não arcava com a atribuição de reduzir as consequências negativas da globalização e criava um discurso que transferia aos próprios indivíduos a incumbência de competir por uma melhor posição no mercado de trabalho.

Importa destacar que os fundamentos da reforma da educação têm suas origens, em 1990, na Conferência Mundial de "Educação para Todos", em Jomtein, na Tailândia, a qual foi financiada por agências multilaterais, como a Organização das Nações Unidas para a Educação, a Ciência e a Cultura (UNESCO), o Banco Mundial (BM) e o Fundo das Nações Unidas para a Infância (UNICEF). Nesse evento, foi elaborada a Declaração Mundial de Educação Para Todos, com o objetivo de incentivar o compromisso mundial com a educação de todos os cidadãos até 2025. Os 155 países, que assinaram a Carta de Jomtien comprometeram-se com a garantia da educação para todos, principalmente, a Educação Básica. Contudo, Shiroma, Moraes e Evangelista (2011, p. 52, grifo nosso) ressaltam os problemas enfrentados pelo Brasil no momento de pôr em prática tais ideias:

Um primeiro problema aqui enfrentado refere-se à expressão "para todos" que sugeria uma universalização da educação básica, que no Brasil compreende desde a educação infantil até o ensino médio, 
que a Conferência não pretendia. Em segundo lugar, alguns autores compreenderam o conceito $\mathrm{NEBA}^{3}$ em sua função ideológica de indicar a natureza do ensino a ser ministrado. Isto é, para estratos sociais diferentes, ensino diferentes, uma vez que as necessidades básicas de um e outro não poderiam ser as mesmas.

Ao ponderar que a educação se moldaria aos estratos sociais, Shiroma, Moraes e Evangelista (2011) evidenciam o dualismo da educação brasileira. Ora, se as camadas mais carentes da população têm necessidades peculiares, elas precisariam receber um atendimento diferenciado daquele demandado pela clientela mais abastada. Esse dualismo será reforçado pela Reforma da EP, em 1997.

Conforme Frigotto (2006), a Declaração de Jomtein, aspirando à entrada do trabalhador no contexto globalizado, afirmava ser preciso uma formação voltada ao desenvolvimento de competências e de habilidades. Tais recomendações eram necessárias, pois, com a internacionalização da economia, a educação torna-se fator decisivo para o desenvolvimento econômico, gerando condições de competitividade entre os países. Desse modo, o autor relaciona a EP a tais reformas estruturais, pois:

As políticas de educação escolar e de formação técnico-profissional que se consolidaram na hegemonia neoliberal buscaram, não sem contradições, a produção das qualificações necessárias ao funcionamento da economia nos setores restritos que exigem trabalho complexo, o alargamento da formação para o trabalho simples e a formação de quadro para a elaboração e a disseminação da pedagogia da hegemonia (FRIGOTTO, 2006, p. 266).

Diante disso, a EP seguiu as políticas de ajustes do Estado, com redução dos gastos, cursos modulados e de curta duração, buscando atender às necessidades do mercado, agora alimentado pelas transformações decorrentes da globalização (OLIVEIRA, 2003). O discurso meritocrático ganha espaço na sociedade, de modo que a não inserção no mercado de trabalho devia-se à ineficiência do trabalhador.

[...] o discurso da empregabilidade e flexibilidade das relações de trabalho ganhou espaço. Dentro da lógica neoliberal, tais conceitos

\footnotetext{
3 Segundo as autoras, o conceito Necessidades Básicas de Aprendizagem (NEBA) refere-se àqueles conhecimentos teóricos e práticos, capacidades, valores e atitudes indispensáveis ao sujeito pra enfrentar suas necessidades básicas em sete situações: 1) a sobrevivência; 2) o desenvolvimento pleno de suas capacidades; 3) uma vida e um trabalho dignos; 4) uma participação plena no desenvolvimento; 5) a melhoria da qualidade de vida; 6) a tomada de decisões informadas; 7) a possibilidade de continuar aprendendo.
} 
expressam o caráter limitado da promessa integradora. Afinal, já que não há espaço para todos no mercado, cabe a cada indivíduo adquirir no próprio mercado a sua formação. Dito de outra forma, a posse do conhecimento para colocar-se à disposição do mercado cabe a cada um obter. No plano econômico, a integração de indivíduos será facilitada, ainda segundo a lógica dominante, se o Estado flexibilizar as relações de trabalho, reduzindo os encargos sociais e permitindo a "livre negociação" (GOMES et al (2014, p. 262).

Portanto, a Reforma da EP, na década de 1990, acompanhava 0 caminho das mudanças no modelo de reorganização da sociedade capitalista, orientada por reformas que envolveram a redefinição do papel do Estado, as políticas sociais, a democracia e o desenvolvimento.

Não nos surpreende que, na elaboração da nova Lei de Diretrizes e Bases da Educação Nacional (LDB), ficassem evidenciados os vários interesses em disputa. Após a promulgação da Constituição Federal, em 1988, o deputado Octávio Elísio apresentou o projeto de lei da nova LDB na Câmara Federal, oriundo de um texto escrito pelo professor Demerval Saviani. Esse documento trazia a noção de politecnia, destacando a vinculação da educação ao mundo do trabalho e à prática social. Tratavase de garantir um ensino politécnico associado a uma educação geral que fosse única para todos os brasileiros.

Entretanto, o processo foi interrompido pelo projeto apresentado pelo Senador Darcy Ribeiro, que, segundo Martins (2000), foi elaborado com a ajuda do primeiro escalão do MEC e recusava a contribuição das entidades representativas da educação nacional e de especialistas da área envolvidos com o processo de construção da nova LDB.

Em dezembro de 1996, foi aprovada a Lei $n^{\circ} 9.394 / 1996$, apresentada como uma LDB moderna, visando o desenvolvimento do país rumo ao século XXI. Enquanto isso, Darcy Ribeiro tecia comentários laudatórios, anunciando a flexibilidade da lei, sua adequação às exigências do mundo moderno e o seu minimalismo (SHIROMA; MORAES; EVANGELISTA, 2011 ).

Na concepção dos educadores e entidades excluídos do processo de elaboração, a atual LDB é marcada pelo seu caráter genérico, flexível e descentralizador, pois muitos dos seus artigos careciam de regulamentação. Nesse sentido, Frigotto e Ciavatta (2003, p. 110) afirmam que "Todas as 
decisões fundamentais foram sendo tomadas pelo alto, pelo Poder Executivo, por meio de medidas provisórias, decretos ou por leis conquistadas no Parlamento mediante o expediente da troca de favores".

Para Saviani (201 la, p. 226), trata-se uma "LDB minimalista" adequada ao Estado mínimo, congruente com a ideologia neoliberal de privatizações, de valorização dos mecanismos de mercado e desregulamentação das leis trabalhistas.

A LDB, apesar de ter sido pioneira no uso da expressão "Educação Profissional", não abordou essa modalidade de maneira aprofundada. $O$ governo Fernando Henrique Cardoso, com a flexibilização assumida pela nova LDB, passou a adotar um conjunto de medidas produzidas por especialistas, tecnocratas e técnicos, que deliberam as políticas de "cima para baixo" de acordo com os princípios de ajustes da sociedade às necessidades do capital (FRIGOTTO; CIAVATTA, 2003).

Lima Filho (2002) considera que o maior prejuízo social ocasionado pela LDB foi a fragmentação das modalidades e níveis educacionais, significando a renúncia da possibilidade de construção de um Sistema Nacional de Educação. Isso se deve ao fato de a Educação Profissional ter ficado restrita ao Capítulo III do Título V, em, apenas, quatro artigos:

Art. 39. A educação profissional, integrada às diferentes formas de educação, ao trabalho, à ciência e à tecnologia, conduz ao permanente desenvolvimento de aptidões para a vida produtiva.

Parágrafo Único. O aluno matriculado ou egresso do ensino fundamental, médio e superior, bem como o trabalhador em geral, jovem ou adulto, contará com a possibilidade de acesso à educação profissional.

Art. 40. A educação profissional será desenvolvida em articulação com o ensino regular ou por diferentes estratégias de educação continuada, em instituições especializadas ou no ambiente de trabalho.

Art. 41. O conhecimento adquirido na educação profissional, inclusive no trabalho, poderá ser objeto de avaliação, reconhecimento e certificação para prosseguimento ou conclusão de estudos.

Parágrafo Único. Os diplomas de cursos de educação profissional de nível médio, quando registrados terão validade nacional.

Art. 42. As escolas técnicas e profissionais, além dos cursos regulares, oferecerão cursos especiais, abertos à comunidade, condicionada a matrícula à capacidade de aproveitamento e não necessariamente ao nível de escolaridade (BRASIL, 1996 grifo nosso). 
Como podemos perceber no parágrafo único do Artigo 39, a EP é apresentada como uma modalidade de educação desvinculada do ensino regular, fato reforçado no Artigo 40 ao se utilizar a palavra "articulação" e não "integração" entre o Ensino Médio e a EP. É elucidativa a análise feita por Lima Filho (2002. p. 182).

Esta genérica e imprecisa articulação pode ser tão frágil ou diminuta que reduz ao mínimo a educação regular, ou mesmo dispensa a sua obrigatoriedade, pois nota-se que o uso do conectivo "ou" na redação desse artigo dá à educação profissional o caráter alternativo de substituir a articulação com o ensino regular por diferentes estratégias em instituições especializadas ou ambiente de trabalho, abrindo a possibilidade para que a educação profissional se realize de modo instrumental e desvinculado dos saberes científicos e da dimensão ético-política do processo educativo, com risco de reduzir-se a mero treinamento ou adestramento de mão-deobra.

Fica, dessa maneira, presente na LDB, a aproximação da EP às propostas neoliberais, alimentadas pela globalização e pela flexibilização, requisitando uma capacitação de trabalhadores de modo que estes se adaptem à rapidez e à competitividade do mercado.

Não por acaso, em 7 de março de 1996, portanto, em paralelo à elaboração da LDB, foi apresentado, pelo então ministro da educação, Paulo Renato Souza, o Projeto de Lei $n^{\circ}$ 1.603/1996, propondo uma reestruturação da EP, principalmente na Rede Federal, aspirando ao ajuste da formação do trabalhador às necessidades do setor produtivo. As transformações solicitadas objetivavam adequar $O$ ensino técnicoprofissional às mudanças tecnológicas em fluxo e que se encontravam no conjunto das reformas institucionais e políticas sociais (LIMA FILHO, 2002).

Segundo Kuenzer (2001), esse PL foi elaborado por uma equipe isolada no MEC, sem embasamento teórico e clareza. A razão para isso estava no acordo realizado entre MEC e a Secretaria Nacional de Educação Média e Tecnológica/SEMTEC e o Banco Internacional de Desenvolvimento (BID), pois este, por financiar a Reforma, impunha as suas condições para a liberação de recursos.

O PL n $1.603 / 1996$ objetivava a separação entre a formação geral e a profissional de nível médio, pretendendo maior flexibilidade curricular, de 
maneira a proporcionar sua rápida adaptação às demandas do mercado. O documento recomendava que a EP seria desenvolvida em articulação com o ensino regular ou em modalidades que contemplassem estratégias de educação continuada, podendo ser ofertada em instituições especializadas ou nos ambientes de trabalho (SILVEIRA, 2010).

A EP passaria a compreender três níveis: básico, destinado à qualificação profissional do trabalhador, sem exigir escolaridade prévia; técnico (médio), destinado a oferecer habilitação a alunos matriculados ou egressos do nível médio; e tecnológico (graduação), estruturado para atender aos diversos setores da economia, abrangendo áreas especializadas. Lima Filho (2002, p. 165-166) explica como isso funcionaria na prática:

[...] O ensino técnico integrado ao ensino médio tornar-se-ia separado e organizado independentemente e passaria a ser ofertado de modo concomitante ou sequencial a este. Ademais, os cursos técnicos passariam a ser estruturados por meio de módulos independentes e dotados de terminalidade. A conclusão de cada módulo conferiria um Certificado de Qualificação específica e a conclusão de um conjunto de módulos articulados em currículo pleno, que poderiam ser cursados em instituições distintas, daria direito à habilitação de Técnico de Nível Médio, desde que o período transcorrido entre a conclusão do primeiro módulo e do último não excedesse a cinco anos.

Para o autor em tela, tais medidas pretendiam, de acordo com a Exposição de Motivos $n^{\circ} 37 / 1996$, desenvolver a flexibilidade do modelo, diminuir os custos do sistema, elevar a cobertura, ajustar a oferta às demandas do setor produtivo e simplificar a alternância entre escola e emprego. Ressalta que a forma pela qual o PL $n^{\circ} 1.603 / 1996$ foi elaborado e conduzido - com a pressa legislativa do MEC e sem a participação dos setores diretamente ligados à EP e da comunidade acadêmica -, rendeu muitas críticas, particularmente, do Fórum Nacional em Defesa da Escola Pública. Em função das polêmicas, o MEC solicitou à Câmara dos Deputados a sua retirada da pauta de votação.

Todavia, essa decisão não é vista por Frigotto (2012) como resultado das críticas ao conteúdo do PL, mas pelo fato de o Poder Executivo perceber que poderia transformar o seu conteúdo em decreto. Assim é que, 
utilizando-se de sua competência e base política, dois meses depois de arquivado o PL, o governo o editou, em abril de 1997, sob a forma de decreto, de $n^{\circ} 2.208 / 1997$, que, regulamentado pelas Portarias n 646/1997 e n 1005/1997, promoveu a Reforma da EP.

Para justificar essa Reforma, a cúpula do governo alegou que os cursos da Rede Federal eram caros, elitizantes, de longa duração e não atendiam às demandas dos setores produtivos, descaracterizando, assim, a função que, para eles, deveria ter a EP: qualificar mão de obra para o mercado de trabalho. Argumentavam ainda que uma parte significativa dos egressos se direcionava aos estudos no ensino superior, não ingressando de imediato no mercado de trabalho (LIMA FILHO, 2002).

Conforme Saviani (2011a, p. 144), as agências multilaterais assim justificavam a necessidade de uma reforma na EP:

a) redução de custos, por meio de cursos curtos, supostamente demandados pelo mercado;

b) descompromisso do Estado com o financiamento da educação pública, para além do ensino fundamental;

c) racionalização dos recursos existentes nos Centros Federais de Educação Tecnológica (CEFETs) e Escolas Técnicas Federais (ETFs), consideradas escolas muito caras de preparação para o ensino superior;

d) repasse de recursos púbicos para empresas privadas para que assumam, em lugar do Estado, a educação dos trabalhadores:

e) fomento à iniciativa privada propriamente dita.

Com o objetivo de regulamentar o inciso $2^{\circ}$ do Artigo 36 e os Artigos de 39 a 42 da LDB, O Decreto $n^{\circ} 2.208 / 1997$ constituiu o principal instrumento jurídico-normativo da Reforma e instituiu mudanças na oferta da EP no Brasil. A principal delas refere-se à formação técnica, que dispôs de organização curricular distinta do Ensino Médio.

O Decreto $n^{\circ} 2.208 / 1997$ estava estruturado em doze artigos que, pela importância desse documento para este texto, discorreremos sobre cada um deles.

No primeiro, eram apresentados os objetivos gerais da EP:

I - promover a transição entre a escola e o mundo do trabalho, capacitando jovens e adultos com conhecimentos e habilidades gerais e específicas para o exercício de atividades produtivas;

II - proporcionar a formação de profissionais, aptos a exercerem atividades específicas no trabalho, com escolaridade correspondente aos níveis médio, superior e de pós-graduação; 
III - especializar, aperfeiçoar e atualizar o trabalho em seus conhecimentos tecnológicos;

IV - qualificar, reprofissionalizar e atualizar jovens e adultos trabalhadores, com qualquer nível de escolaridade, visando a sua inserção e melhor desempenho no exercício do trabalho. (BRASIL, 1997a).

Portanto, O Decreto deixava evidente que a EP pretendia, prioritariamente, a aproximação entre a escola e o setor produtivo, garantindo formação profissional em diversos níveis de escolaridade, com o intuito de responder a um mercado cada vez mais exigente.

O Artigo $2^{\circ}$ reproduzia o conteúdo do Artigo 40 da LDB, que trata da oferta da EP. Esta poderia ser feita em parceria com as escolas regulares, em cursos de formação continuada, em espaços especializados ou nas empresas.

O Artigo $3^{\circ}$ apresentava os níveis da EP tal qual estavam presentes no PL n 1.603/1996: o básico, voltado à qualificação e reprofissionalização de trabalhadores, independente de escolaridade prévia; o técnico, destinado a habilitar profissionalmente alunos matriculados ou egressos do ensino médio; e o tecnológico, em nível superior na área tecnológica.

Pelo Decreto, o nível básico, por garantir uma ocupação para os trabalhadores, independentemente do grau de estudo, não necessitaria, de acordo com o artigo $4^{\circ}$, de regulamentação curricular e teria duração variável. Seus cursos, obrigatoriamente, deveriam ser ofertados pelas instituições financiadas pelo governo e, ao final, dariam direito a um certificado de qualificação profissional. Logo, na prática, as ofertas nas Escolas Técnicas Federais passariam a seguir o modelo dos cursos oferecidos pelo Serviço Nacional de Aprendizagem Industrial (SENAI).

Artigo $5^{\circ}$ estabelecia duas formas para ofertas dos cursos técnicos: concomitante e sequencial. Na primeira, permitia-se ao aluno cursar, ao mesmo tempo, o Ensino Médio e um curso técnico, mas com matrículas e currículos separados, podendo os dois cursos serem realizados na mesma instituição ou em instituições diferentes. A forma sequencial destinava-se a quem já havia concluído o Ensino Médio e desejava seguir os estudos por meio de um curso técnico (BRASIL, 1997a). 
O conteúdo desse artigo é um dos mais polêmicos da Reforma, pois não só separou o ensino propedêutico do ensino técnico como criou duas formas de oferta para a EP. O Decreto $n^{\circ} 2.208 / 1997$, ao estabelecer tais formas de articulação da EP com o Ensino Médio, não considerou as especificidades das instituições envolvidas, principalmente, para realizar a concomitância.

O Artigo $6^{\circ}$ tratava da forma de elaboração dos currículos plenos dos cursos do ensino técnico, ficando sob a responsabilidade do MEC, ouvido o Conselho Nacional de Educação, estabelecer "[...] diretrizes curriculares nacionais, constantes de carga horária mínima do curso, conteúdos mínimos, habilidades e competências básicas, por área profissional" (BRASIL, 1997a).

Salientamos a importância que a pedagogia das competências teve na implantação da Reforma da EP, haja vista o comprometimento que passava a ter essa modalidade de ensino com o processo de acumulação capitalista. O regime de acumulação flexível exige trabalhadores com competências diversificadas e capazes de se adaptar às cadeias produtivas e enfretar os eventos não previstos, daí o uso de metodologias que os treinem de modo a saber enfrentar e solucionar problemas. Considerando que a ideologia neoliberal passou a guiar as políticas educativas, o discurso meritocrático naturalizou as diferenças entre as classes sociais e os sujeitos: os empregos destinam-se aos "mais competentes", aos "mais capazes", aos que souberam "vestir a camisa da empresa". Cabe aos "menos competentes" seguir esse caminho e buscar uma (re)qualificação que oportune uma vaga no mercado de trabalho, mesmo que esta tenha data de validade, pois logo terá alguém "mais capacitado" que eles.

O Artigo $7^{\circ}$ definia como condição para a elaboração das diretrizes curriculares a realização de "[...] estudos de identificação do perfil de competências necessárias à atividade requerida, ouvidos os setores interessados, inclusive trabalhadores e empregadores" (BRASIL, 1997a).

No Artigo $8^{\circ}$, encontramos que os cursos seriam formados por módulos (subcursos), com certificações próprias e reconhecidas pela soma das certificações de cada módulo concluído. O aluno poderia realizar um curso 
em módulos autônomos, até mesmo em instituições diferentes, sendo o diploma expedido pela instituição em que ele concluiu o último módulo.

O fato de o currículo estar organizado em módulos e ter caráter de terminalidade para efeito de qualificação profissional, demonstra a pressa na formação de mão de obra, encoberta pelo discurso da democratização da educação, da garantia da empregabilidade e da inclusão. Como destaca Kuenzer (2007, p. 1165), para os trabalhadores periféricos, a formação na educação básica "assume o caráter de preparação geral que viabiliza treinamentos aligeirados, com foco nas diferentes ocupações em que serão inseridos ao longo das trajetórias laborais, em diferentes pontos de distintas cadeias produtivas". Para ela, essa educação incompleta, resulta em formação final e contribui para a flexibilidade por meio da desqualificação.

É o que temos chamado, em outros textos, de exclusão includente na ponta do mercado, que exclui para incluir em trabalhos precarizados ao longo das cadeias produtivas, dialeticamente complementada pela inclusão excludente na ponta da escola, que, ao incluir em propostas desiguais e diferenciadas, contribui para a produção e para a justificação da exclusão. Ou seja, a dualidade estrutural, embora negada na acumulação flexível, não se supera, mantendo-se e fortalecendo-se, a partir de uma outra lógica (KUENZER, 2007, p. 1165).

Além disso, a fragmentação do currículo em módulos pode parecer, à primeira vista, uma contradição no Decreto, pois, se a realidade produtiva exigia um trabalhador flexível, facilmente adaptável, isso não seria possível com a modularização. Seriam incompetentes os elaboradores da Reforma da EP? A resposta de Kuenzer (1997, p. 95) é não:

Então, qual a lógica escondida sob esta aparente incompetência? A da mera redução de custos através de uma pretendida aproximação do mercado que "demandaria" cursos curtos, do descompromisso crescente do Estado com o financiamento da educação pública para além do fundamental, da racionalização do uso dos recursos existentes nos CEFETs e ETFs, escolas muito caras para preparar para o ensino superior, do repasse de recursos públicos para as empresas privadas como estímulo para que assumam as funções do Estado relativas à educação dos trabalhadores, inclusive a básica (o que certamente é mais barato), e do fomento à privatização propriamente dita.

O Artigo $9^{\circ}$ estabelecia, como critério principal de seleção para lecionar nos cursos técnicos, a experiência profissional dos professores, 
prevendo formação para o magistério, previamente ou em serviço, por meio de cursos regulares de licenciaturas ou de programas de formação pedagógica.

Esse artigo revela o caráter emergencial e descontínuo que caracteriza a história da formação de professores para a EP no Brasil. Ao tratar desse tema, Maldaner (2017, p. 191) observa que "é preciso reconhecer que a docência na EPT é muito mais que mera transmissão de conhecimentos empíricos ou processo de ensino de conteúdos fragmentados e esvaziados teoricamente".

O Artigo $10^{\circ}$ dispôs sobre os cursos superiores, de nível tecnológico, devendo ser estruturados para atender aos diversos setores da economia, abrangendo áreas especializadas e conferindo o diploma de Tecnólogo.

O Artigo $11^{\circ}$ designava aos sistemas federal e estaduais de ensino a execução de exames para certificar competência, a fim de conferir dispensa de disciplinas ou módulos em cursos de habilitação do ensino técnico. Ou seja, mais uma vez fica patente o esforço por uma formação rápida sob o subterfúgio da flexibilidade e da empregabilidade.

Por fim, o Artigo $12^{\circ}$ determinava que o Decreto entraria em vigor na data de sua publicação.

No mês seguinte à publicação do Decreto n 2.208/1997, foi lançada a Portaria n 646/1997, destinada à Rede Federal de Educação Tecnológica. A Portaria estabelecia, no Artigo $1^{\circ}$, que a implementação do dispositivo "[...] far-se-á, na rede federal de educação tecnológica, no prazo de até quatro anos", seguindo o "plano de implementação" da Reforma da EP, a ser elaborado por cada instituição, prevendo, conforme o artigo $2^{\circ}$, a oferta de:

I- cursos de nível técnicos, desenvolvidos concomitantemente com o ensino médio, para alunos oriundos de escolas dos sistemas de ensino;

Il- cursos de nível técnico destinados a egressos de nível médio, por via regular ou supletiva;

III- cursos de especialização e aperfeiçoamento para egressos de cursos de nível técnico;

IV- cursos de qualificação, requalificação, reprofissionalização de jovens, adultos e trabalhadores em geral, com qualquer nível de escolarização (BRASIL, 1997b). 
Além de legalizar a dualidade entre o Ensino Médio e o técnico, e a formação rápida de mão de obra, a Portaria n 646/1997, no seu Artigo 3, possibilitava às instituições federais de educação tecnológica, a manutenção do Ensino Médio, desde que "[...] com matrícula independente da educação profissional, oferecendo o máximo de $50 \%$ do total de vagas oferecidas para os cursos regulares em 1997, observando o disposto na Lei $n^{\circ}$ 9.394/1996" (BRASIL, 1997b). Percebe-se, com isso, a pressão do MEC sobre essas instituições para que adotassem as suas "orientações". As "opções" existiam, mas eivadas de prejuízos e temores, sobretudo para os docentes das disciplinas da formação geral.

O Artigo $4^{\circ}$ tratava do Plano de Implementação da Reforma. Previa um incremento de vagas em relação às oferecidas em 1997 no ensino regular de, no mínimo, $50 \%$ no período de até 5 anos. Mas, no parágrafo $2^{\circ}$, registrava que "no cálculo do incremento das vagas previsto no caput deste artigo, considerar-se-á apenas a matrícula no ensino médio e nos cursos mencionados nos incisivos I e II deste artigo", isto é, nos cursos de ensino técnico nas formas concomitante ou sequencial ao Ensino Médio (BRASIL, 1997b), reforçando o divórcio entre a formação geral e a profissional e as pressões sobre as instituições de EP e os seus gestores.

A Portaria $n^{\circ}$ 646/1997 definia o papel a ser desempenhado pelas instituições da Rede de Educação Tecnológica, que deverão, de acordo com o Artigo 11, "[...] se constituir em centros de referência, inclusive com papel relevante na expansão da Educação Profissional conforme previsto no Artigo n 44 da Medida Provisória n. ${ }^{\circ}$ 1.549-29, de 15 de abril de 1997" (BRASIL, 1997b).

Segundo Silveira (2010), como efeitos dessas mudanças, houve uma queda da qualidade no ensino. Porém, a procura pelos cursos técnicos ofertados pelos CEFET e pelas escolas técnicas da rede pública federal ainda era significativa.

Seguindo o plano de reforma, em dezembro de 1997, O MEC, em parceria com o Ministério do Trabalho, lançou a Portaria n 1005/1997(BRASIL, 1997c), criando o Programa de Expansão da Educação Profissional (PROEP). 
Esse Programa visava criar um sistema de EP abrangendo aspectos técnicopedagógicos, como a flexibilização curricular e a obtenção de recursos e parcerias, de modo a assegurar a expansão da Rede de EP no Brasil. Para isso, dispunha de 500 milhões de dólares, sendo 250 milhões obtidos por empréstimos do BID, 125 milhões do Fundo de Amparo ao Trabalhador (FAT) e 125 milhões do orçamento do MEC.

A incumbência do PROEP para a Rede Federal era reformulá-la no "[...] ponto de vista de suas ofertas educacionais, da gestão e das relações empresariais e comunitárias na perspectiva de torná-la competitiva no mercado educacional" (BRASIL, 2007, p. 20). Pretendia-se que, no prazo de cinco anos, essas escolas dispusessem de recursos próprios, provindos da prestação de serviços à comunidade, para se autofinanciar e, assim, o Estado gradualmente isentar-se de parte dos custos com sua manutenção. Portanto, uma tentativa clara de impor na educação as ideias neoliberais pautadas na qualidade total, na empregabilidade e na competitividade e, ao mesmo tempo, reduzir os investimentos do Estado em setores sociais.

Para que as escolas da Rede Federal tivessem acesso ao financiamento proveniente do PROEP exigia-se, dentre outras medidas, a separação entre o Ensino Médio e o técnico, como previa o Decreto $n^{\circ}$ 2.208/1997 e a Portaria n 646/1997. Para Silveira (2010) e Cunha (2005), o PROEP representou o poder de barganha do governo, que, ao dispor de 500 milhões de dólares, induziu as instituições a aderirem a Reforma da EP. Num cenário de costes de gastos públicos e de privatizações, podemos imaginar o que representava, para as instutuições de EP, a possibilidade de conseguir uma parte desse recurso.

A separação entre o Ensino Médio e o Técnico, para Saviani (201 la, p. 144),

[...] significou voltar atrás no tempo, não apenas em relação à Lei n. 5.692 de 1971, mas em relação à LDB de 1961, já que esta flexibilizou a relação entre os ramos do ensino médio então, permitindo a equivalência e o trânsito entre eles, quebrando, assim, a "dualidade de sistema" próprio das reformas Capanema da década de 1940, na vigência do Estado Novo. Ora, é a essa dualidade que se retornou com o Decreto n. 2.208, de 17 de abril de 1997. 
Da mesma forma que Saviani (2011a), Frigotto, Ciavatta e Ramos (2012) avaliam que o Decreto $n^{\circ} 2.208 / 1997$ representou uma regressão ao dualismo, visto que se cristalizou a separação entre as dimensões técnicas e políticas, específicas e gerais, particulares e universais. Tais constatações tornam visível a estrutura contraditória e indócil do capital, uma vez que se apoia no discurso de que a educação é a "cura" das desigualdades sociais, sendo fator fundamental do desenvolvimento econômico, exigindo da educação que assuma uma nova conotação, como a de escolas dualistas e, por isso mesmo, excludentes.

Assim, o governo Fernando Henrique Cardoso, por intercessão do MEC, aderiu ao pensamento pedagógico empresarial que consiste em uma "[...] perspectiva pedagógica individualista, dualista e fragmentária coerente com o ideário da desregulamentação, flexibilização e privatização e com o desmonte dos direitos sociais [...]" (FRIGOTTO, CIAVATTA, 2003, p. 108).

O Decreto $n^{\circ}$ 2.208/1997 teve sete anos de vigência, sendo extinto, em 2004, por meio do Decreto n 5.154 exarado pelo então presidente Luis Inacio Lula da Silva. O novo Decreto permitiu a integração entre o Ensino Médio e o Técnico a partir da forma integrada. Contudo, a legislação da EP manteve as formas concomitante e subsequente, gerando críticas ao governo Lula por parte de educadores progressistas que viam na ascenção de um governo popular a oportunidade de reverter por completo o aprofundamento do ideário neoliberal.

Apesar desse desapontamento, o Ensino Médio Integrado (EMI) tornouse a bandeira de luta daqueles que defendem uma EP assentada em princípios que conduzam à emancipação dos sujeitos jovens e adultos, de modo a fortalecer uma EP pautada na imbricação dos eixos trabalho, educação, ciência e cultura.

\section{CONSIDERAÇÕES FINAIS}

Neste artigo, abordamos a Reforma da EP empreendida no governo Fernando Henrique Cardoso, em decorrência da penetração da política neoliberal, a qual também promoveu a Reforma do Estado, retirando deste 
- papel de interventor direto nas ações para tornar-se regulador. A legislação criada à época serviu de fonte para nossa análise. Procuramos, nas entrelinhas, perceber as demandas do mercado na escrita desses documentos.

No cenário de fins do Século XX, a hegemonia neoliberal fez da EP um instrumento de apoio para a inserção do Brasil na economia globalizadas e nos mercados competitivos, daí a influência direta das agências multilaterais nas orientações das políticas educacionais de modo a produzir uma educação, de curta duração e rentável ao capital. Desse modo, "[...] tanto a quantidade como a qualidade da mão de obra formada é determinada pelos interesses de curto prazo do capital" (GOMES et al, 2014, p. 262).

Ao se guiar pela agenda neoliberal, mais preocupada com as demanadas do mercado, esse modelo de educação não tinha o trabalho como princípio educativo e seguia a contrapelo da educação politécnica na qual teoria e prática andam juntas. Ao contrário disso, a legislação criada pela Reforma da EP, reforçou a dualidade estrutural, impôs a pedagogia das competências, limitou o caráter emancipatório das práticas educativas e legitimou a inclusão excludente.

Por fim, esperamos que os educadores comprometidos com uma EP emancipatória empreendam esforços no enfrentamento dos resquícios ainda existentes da Reforma da EP e na luta contra hegemônica de combate ao projeto neoliberal que, no atual cenário, volta fortalecido pelas mãos da extrema direita.

\section{REFERÊNCIAS}

BARROS, J. A. A fonte histórica e o seu lugar de produção. Petrópolis: Vozes, 2020. BRASIL. Presidência da República. Casa Civil. Plano Diretor da Reforma do Aparelho do Estado. Brasília: Presidência da República, DF, Imprensa Nacional, 1995. Disponível em:

http://www.biblioteca.presidencia.gov.br/publicacoesoficiais/catalogo/fhc/planodiretor-da-reforma-do-aparelho-do-estado-1995.pdf Acesso em: 8 jul. 2021.

BRASIL. Presidência da República. Casa Civil. Lei $n^{\circ}$. 9.394, de 20 de dezembro de 1996. Estabelece as diretrizes e bases da educação nacional. Brasília: Presidência da República, DF, 1996. Disponível em: 
http://portal.mec.gov.br/seesp/arquivos/pdf/lei9394_ldbn1.pdf Acesso em: 8 jul. 2021.

BRASIL. Presidência da República. Casa Civil. Decreto $n^{\circ} 2.208$, de 17 de abril de 1997. Regulamenta o §2. ${ }^{\circ}$ do artigo 36 e os artigos 39 a 42 da Lei 9.394 , de 20 de dezembro de 1997, que estabelece as diretrizes e bases da educação nacional. Brasília: Presidência da República, DF, 1997a. Disponível em:

http://www.planalto.gov.br/ccivil_03/decreto/d2208.htm Acesso em: 8 jul. 2021.

BRASIL. Ministério da Educação. Portaria n 646, de 14 de maio de 1997.

Regulamenta a implantação do disposto nos artigos 39 a 42 da Lei Federal $n^{\circ}$

9.394/96 e no Decreto n².208/97 e dá outras providências. Brasília, DF: Ministério da Educação, 1997b. Disponível em:

http://portal.mec.gov.br/setec/arquivos/pdf/PMEC646_97.pdf Acesso em: 8 jul. 2021.BRASIL. Ministério da Educação. Portaria n 1005, de 10 de dezembro de 1997. Implementa o Programa de Reforma da Educação Profissional - PROEP. Brasília, DF: Ministério da Educação, 1997c. Disponível em:

http://portal.mec.gov.br/setec/arquivos/pdf/PMEC 1005_97.pdf Acesso em: 8 jul. 2021.

BRASIL. Ministério da Educação. Educação Profissional Técnica de Nível Médio Integrada ao Ensino Médio: documento base. Braślia, DF: Ministério da Educação, 2007. Disponível em:

http://portal.mec.gov.br/setec/arquivos/pdf/documento_base.pdf Acesso em: 8 jul. 2021.

BRESSER-PEREIRA, L. C. Crise econômica e reforma do Estado no Brasil. São Paulo: editora 34, 1996.

BRESSER-PEREIRA, L. C. A Reforma do Estado dos anos 90: lógica e mecanismos de controle. Lua Nova, São Paulo. n. 45, p. 49-95, 1997.

CUNHA, L. A. O Ensino Profissional na Irradiação do Industrialismo. 2. ed. São Paulo: UNESP, Brasília, 2005.

CAIRES, V. G.; OLIVEIRA, M. A. M. Educação Profissional Brasileira: da Colônia ao PNE 2014-2020. Rio de Janeiro: Vozes, 2016.

FRIGOTTO, G. Fundamentos Científicos e Técnicos da Relação Trabalho e Educação no Brasil de Hoje. In: LIMA, J. C. F.; NEVES, L. M. W. (org.). Fundamentos da educação escolar do Brasil contemporâneo. Rio de Janeiro: Fiocruz, 2006. p. 241-288.

FRIGOTTO, G.; CIAVATTA, M. Educação básica no Brasil na década de 1990: subordinação ativa e consentida à lógica do mercado. Educação \& Sociedade, Campinas, v. 24, n. 82, p. 93-130, abr. 2003.

FRIGOTTO, G. Concepções e mudanças no mundo do trabalho e o ensino médio. In: FRIGOTTO, G.; CIAVATTA, M.; RAMOS, M. (org.). Ensino médio integrado: concepção e contradições. São Paulo: Cortez, 2012. p. 57-82.

FRIGOTTO, G..; CIAVATTA, M.; RAMOS, M. A gênese do Decreto n. 5.154/2004: um debate no contexto controverso da democracia restrita. In: FRIGOTTO, Gaudêncio.; CIAVATTA, M.; RAMOS, M. (Org.). Ensino Médio Integrado: concepções e contradições. São Paulo: Cortez, 2012. p. 21-56. 
GENTILI, P. Neoliberalismo e educação: manual do usuário. In. SILVA, T. T.; GENTILI, P. (Org.). Escola S.A.: quem ganha e quem perde no mercado educacional do neoliberalismo. Brasília, DF: CNTE, 1996. p. 9-49.

Gomes, M. A. O. et al. O trabalho como princípio educativo: a atualidade da educação politécnica. Revista Exitus, Santarém, v. 4, n. 1, p. 255- 274, Jan/Jun. 2014.

HAYEK, F. A. O caminho para a servidão. 6. ed. São Paulo: Instituto Ludwig von Mises. Brasil, 2010.

KUENZER, A. Z. O ensino médio no contexto das políticas públicas de educação no Brasil. Revista Brasileira de Educação, Rio de Janeiro, n. 4, p. 77-95,

jan./fev./mar./abr. 1997.

KUENZER, A. Z. Ensino médio e profissional: as políticas do Estado neoliberal. 3. ed. São Paulo: Cortez, 2001.

KUENZER, A. Z. Da dualidade assumida à dualidade negada: o discurso da flexibilização justifica a inclusão excludente. Educação e Sociedade, Campinas, v. 28, n. 100 - Especial, p. 1153-1178, out. 2007.

LIMA FILHO, D. L. A reforma da Educação profissional no Brasil nos anos noventa. 2002. Tese (Doutorado em Educação) - Universidade Federal de Santa Catarina, Florianópolis, 2002.

MARTINS, M. F. Ensino técnico e globalização: cidadania ou submissão? Campinas: Autores Associados, 2000.

MALDANER, J. J. A formação docente para a educação profissional e tecnológica: breve caracterização do debate. Revista Brasileira de Educação Profissional e Tecnológica, Natal, v. 2, n. 13, p. 1-14, 2017.

OLIVEIRA, R. A (des)qualificação da Educação Profissional Brasileira. São Paulo: Cortez Editora, 2003.

SAVIANI, D. A nova lei da educação: trajetória, limites e perspectivas. 12. ed. Campinas, São Paulo: Autores Associados, 2011 a.

SAVIANI, D. Da nova LDB ao FUNDEB: por uma política educacional. 4. ed. Campinas: Autores Associados, $2011 \mathrm{~b}$.

SILVEIRA, Z. S. Contradições entre capital e trabalho: concepções de educação tecnológica na reforma do ensino médio e técnico. Jundiaí: Paco Editorial, 2010.

SHIROMA, O. E.; MORAES, M. C. M.; EVANGELISTA, O. Política Educacional. 4. ed. Rio de Janeiro: Lamparina, 2011.

STAMATTO, M. I. S. A legislação como fonte para a história da educação. In: SOUZA, E. C.; VASCONCELOS, J. G.; CASTRO, C. A. (Org.). História da Educação: memória, arquivos e cultura escolar. Rio de Janeiro: Salvador: Quartet: Uneb, 2012. p. 277-292.

Submissão em: 11 de fevereiro de 2021.

Aprovado em: 27 de julho de 2021.

Publicado em: 04 de agosto de 2021. 